\title{
Cadaveric study of branching pattern of celiac trunk with rare variations
}

\author{
Aditi Dubey ${ }^{1}$, Preeti Shrivastava $^{2 *}$, Amit Sharma $^{3}$ \\ 1,2 Department of Anatomy, North Delhi M unicipal Corporation Medical College and Hindu Rao Hospital, Malkaganj, Delhi, INDIA. \\ ${ }^{3}$ Guru Govind Singh College of Dental Sciences and Research Centre, Burnpur, INDIA.
}

Email: drpreetishrivastava@gmail.com

\section{$\underline{\text { Abstract }}$}

Celiac Trunk (CT) or celiac artery is the major ventral branch of the abdominal aorta supplying the supracolic compartment of the abdomen. Anatomical variations in the branching pattern of Celiac axis have been reported earlier $(1,2,3)$ and are of great surgical importance. Lot of variations was found in the branching pattern of CT during routine cadaveric dissection in the department of Anatomy, North Delhi Municipal Corporation Medical College and Hindu Rao Hospital, Delhi. Hence, a study was taken up to dissect and examine 10 cadavers available in the department. The CT was studied for accessory branches and their pattern of emergence. Length of each branch was measured and appropriate photographs were taken. In this study trifurcation of celiac trunk is seen in (70\%; 7 out of 10 cases), bifurcation in (10\%; 1 out of 10 cases), pentafurcation in (10\%; 1 out of 10 cases) and heptafurcation also in (10\%; 1 out of 10 cases). Tetrafurcating, Hexafurcating and absent celiac trunk was not observed in our study. Rare variations in the CT branching are found in higher proportion than previously reported.

Key Words: Celiac trunk; celiac artery; celiac axis; Anatomic variations; Cadaveric study

Key Message: Some unique branching pattern of celiac trunk have been reported.

*Address for Correspondence:

Dr. Preeti Shrivastava, Department of Anatomy, North Delhi Municipal Corporation Medical College and Hindu Rao Hospital, Malkaganj, Delhi. INDIA.

Email: drpreetishrivastava@gmail.com

Received Date: 19/03/2018 Revised Date: $21 / 04 / 2018$

DOI: https://doi.org/10.26611/1001621

\begin{tabular}{|l|l|}
\hline \multicolumn{2}{|c|}{ Access this article online } \\
\hline Quick Response Code: & $\begin{array}{l}\text { Website: } \\
\text { www.medpulse.in }\end{array}$ \\
\hline & \\
\hline
\end{tabular}

\section{INTRODUCTION}

The celiac trunk is the first major abdominal branch of the aorta, just after it crosses the diaphragmatic aortic hiatus celiac trunk emerges from the ventral aspect of the aorta, at the level of the 12th thoracic and first lumbar vertebrae ${ }^{4}$. Normal branching pattern of CT as described by Von Haller, is that it usually trifurcates into splenic, common hepatic and left gastric arteries ${ }^{5,6}$. It supplies abdominal foregut derivatives; the liver, gallbladder, pancreas and spleen. Diverse classifications of the celiac trunk have been described including the bifurcation of the
CT while the third branch originates from a different artery, and even independent origins of the common hepatic artery, left gastric artery and splenic artery is also noted, which is termed as absence of the celiac trunk ${ }^{7,8,9}$. Two forms of trifurcation have been described: a "true" tripod is considered when the common hepatic artery, left gastric artery and splenic artery have a common origin, constituting a hepatogastrosplenic trunk. When one of these arteries arises before the remaining two in the course of the celiac trunk, it is called a false tripod ${ }^{1}$. A systematic classification proposed by Panagouli et al, includes all the described celiac trunk variations ${ }^{10}$. Knowledge of the branching pattern of celiac trunk is clinically relevant in esophageal, gastroduodenal, hepatic, biliary and pancreatic angiographic and surgical procedures $^{1}$. This cadaveric study revealed various rare variations in the branching pattern of celiac trunk which is important to be reported and documented for the benefit of the surgeons.

\section{MATERIAL AND METHODS}

Dissection was performed on ten cadavers (four female and six male)in the department of Anatomy, North Delhi 
Municipal Corporation Medical College and Hindu Rao Hospital. Cadavers with upper abdominal surgery or abdominal trauma were not included in the study. Through the thoraco-abdominal midline incision, the liver, the stomach, and pancreas were dissected and retracted. Once the common hepatic artery, the left gastric artery and the splenic artery were identified, their course was followed to their site of origin. The presence of a "true tripod" or a "false tripod" was examined. Celiac trunk variations, accessory vessels and site of origin were also recorded. The stomach, large and small bowels and the pancreas were dissected and retracted in order to expose the total length of the abdominal aorta. The vertebral level of the celiac trunk origin was determined by palpation in cephalic direction beginning from the fifth lumbar vertebral body. A measuring scale and thread was used to measure arterial lengths. Photographs of the celiac trunk and its branches were taken using a camera (ONE PLUS, Model A5000. 20MP).

\section{RESULT}

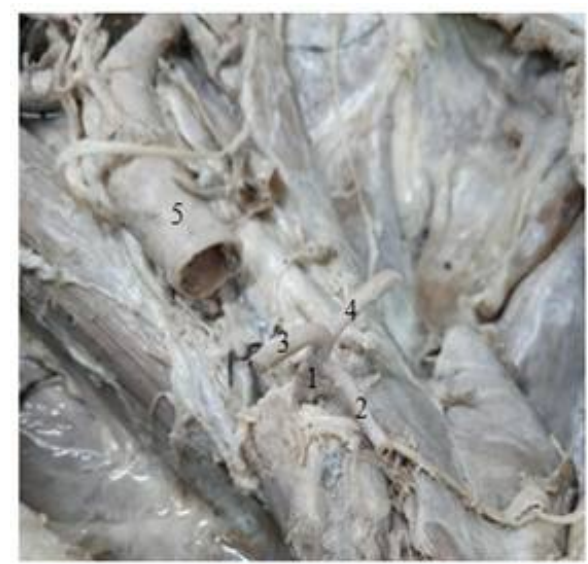

Figure 1:

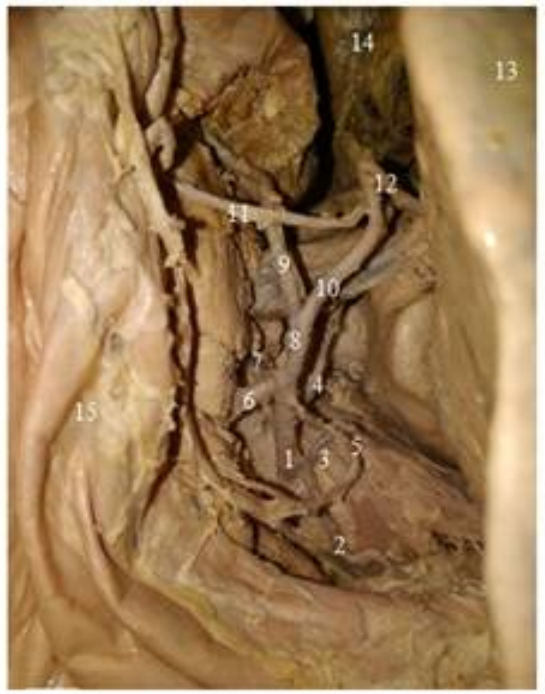

Figure 3:

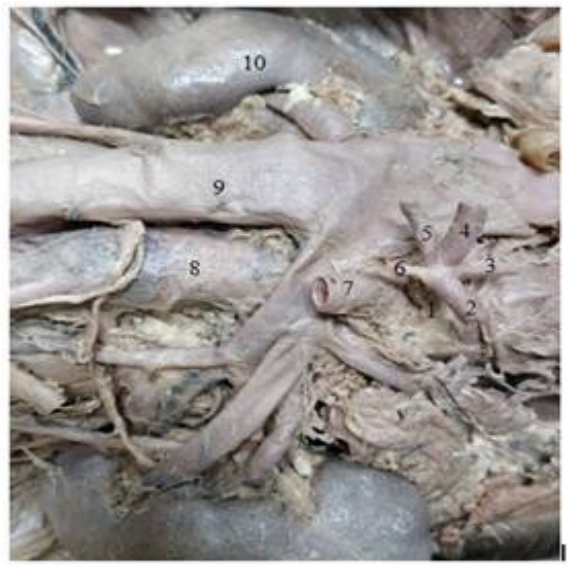

Figure 2:

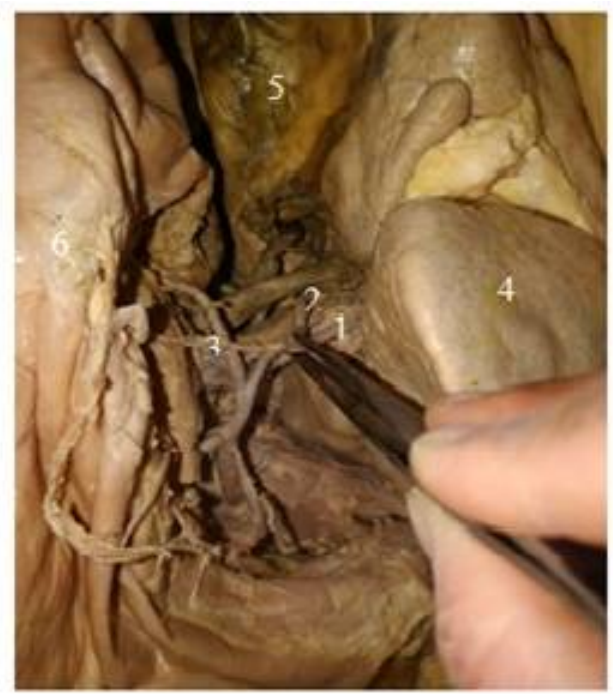

Figure 4:

Figure 1: False Tripod formation of celiac trunk. Left gastric artery arises earlier then CT bifurcates into splenic artery and common hepatic artery. 1- celiac trunk, 2- left gastric artery, 3- splenic artery, 4- common hepatic artery, 5- abdominal aorta.

Figure 2: Pentafurcation of celiac trunk. 1- celiac trunk, 2-left inferior phrenic artery, 3- right inferior phrenic artery, 4- splenic srtery, 5common hepatic artery, 6- left gastric artery, 7- superior mesenteric artery, 8- abdominal aorta, 9- inferior vena cava, 10- kidney.

Figure 3: Heptafurcation/Seven branches of celiac trunk described as type 4.

1-Celiac trunk, 2- left inferior phrenic artery, 3- right inferior phrenic artery, 4- extra right hepatic artery, 5- left gastric artery, 6- splenic artery, 7- pancreatic artery, 8- common hepatic artery, 9- gastroduodenal artery, 10- proper hepatic artery, 11- right gastric artery, 12- left hepatic artery, 13- liver, 14- gall bladder, 15- stomach.

Figure 4: Right gastric arteryarising from left hepatic artery. 1- Left hepatic artery, 2- right hepatic artery, 3- right gastric artery, 4- liver, 5gall bladder, 6- stomach. 
Trifurcation of celiac trunk gives rise to common hepatic artery (CHA), left gastric artery (LGA) and splenic artery (SA) which is designated as type 1 in this study and it was seen in 7 subjects. 5 out of 7 cases of trifurcation of celiac trunk were a true tripod i.e. just after emergence the CT trifurcated into CHA, LGAand SA. Rest of the 2 cases had one artery originating earlier from the $\mathrm{CT}$, and then the CT divided into two branches. In both these cases left gastric artery was the first to arise than common hepatic and splenic artery, a false tripod. Bifurcation of CT into hepato-splenic trunk and left gastric trunk was put in the type 2 category in this study. One case was of this type where the hepato-splenic trunk further divided into splenic artery and common hepatic artery. CHA, in this case, gives rise to proper hepatic artery, gastroduodenal artery and right gastric artery. The left gastric trunk gives rise to left gastroepiploic artery. Additional branches from celiac trunk were observed in 2 caseswhich were described as type 3 and type 4 . Type 3 was pentafurcation of $\mathrm{CT}$ found in a female cadaver. Here, the CT divides into right and left inferior phrenic artery, left gastric artery, splenic artery and common hepatic artery. Type 4 was found in a male cadaver and is one of the most unusual variations. In this case seven branches were arising from celiac trunk. CT total length was $3.5-4 \mathrm{~cm}$. Right and left inferior phrenic artery arise $0.5 \mathrm{~cm}$ distal to the origin of CT. Next branch to arise from CT was an accessory right hepatic artery, $2.4 \mathrm{~cm}$ distal to origin of CT. The left gastric artery was seen to arise $0.5 \mathrm{~cm}$ proximal to the final trifurcation of CT. CT finally trifurcated into splenic artery, a direct branch to pancreas and the common hepatic artery. The common hepatic artery divides into gastroduodenal artery and proper hepatic artery. The gastroduodenal artery continues as right gastroepiploic artery. Proper hepatic artery divides into right and left hepatic artery, left hepatic artery gives rise to right gastric artery in this present study.

\section{DISCUSSION}

The prevalence of CT trifurcating into common hepatic artery, left gastric artery and splenic artery has been found between $40 \%$ and $94.2 \%$ in cadaveric studies ${ }^{1}$. Song et $a l^{11}$ in a radiologicalstudy of 5,002 patients, observed a classic celiac trunk trifurcation in $89.1 \%$ of the patients Panagouli et $a l^{10}$ has reported trifurcation of celiac trunk in $85.1 \%$ cadaveric cases. In contrast, cadaveric studies by Chitra ${ }^{14}$, Nelson et al ${ }^{15}$, Mburu et $a l^{16}$, and Farghadani ${ }^{17}$ reported trifurcated celiac trunk (true tripod) prevalences of $40 \%, 60 \%, 61.8 \%$, and $63.6 \%$, respectively.. In this study celiac trunk trifurcation is observed in majority of cases (70\%; 7 out of 10 cases) but true tripod formation was not seen in all cases. A clear predominance of false tripod over true tripod has been reported $^{18,19}$ but in our study we found true tripod formation in 50\% (5 out of 10) of cases. The most common false tripod is the hepatosplenic trunk, with a left gastric artery emerging first. This is consistent with the findings in our study. Cases have been reported with bifurcated or incomplete celiac trunk, prevalence ranging from $1.3 \%$ to $25 \%{ }^{12}$. The most common types of bifurcation are: hepatosplenic trunk, with the left gastric artery originating from the abdominal aorta (3.34\%), splenogastric and hepatomesenteric trunk (1.9\%) and splenogastric trunk with the common hepatic artery arising from the superior mesenteric artery $(1.13 \%)^{13}$.Celiac trunk bifurcation (type II) constitutes the most common variation of the celiac trunk, with a mean prevalence $7 \%{ }^{10}$. In the present study, only one case was of the type where the hepato-splenic trunk was seen (10\%; 1 out of 10 cases). Additional branches have been referred by Vandamme et $a l^{20}$ as collaterals or tributaries. The most frequent additional branches are single or double inferior phrenic arteries, which have been described in $40 \%$ of cases $^{21}$. In a cadaveric study by Greig et $a l^{22}$, the phrenic arteries originated from the celiac trunk in $46.8 \%$ of the dissections, compared to the abdominal aortic origin, which contributed with $45.1 \%$ of the cases. In the present study, emergence of inferior phrenic artery was observed from the celiac trunk (20\%; 2 cases out of 10). Srivastava $e{ }^{23}$ in a CT-angiographic study found a trifurcated celiac trunk in $28 \%$, bifurcation in $8 \%$, tetrafurcation in $36 \%$, pentafurcation in $20 \%$, and hexafurcation in $4 \%$, while in $4 \%$ the celiac trunk was absent. In this study trifurcation of celiac trunk is seen in (70\%; 7 out of 10 cases), bifurcation in $(10 \% ; 1$ out of 10 cases), pentafurcation in $(10 \% ; 1$ out of 10 cases) and heptafurcation also in $(10 \% ; 1$ out of 10 cases).Tetrafurcating, Hexafurcating and absent celiac trunk was not observed in our study. The types of hepatic artery variation have been described in detail in Michel's classification $^{24}$ and other studies, ${ }^{25,26,27}$ as well as anatomical monographs ${ }^{28}$. There are 10 variants /subtypes of the hepatic arterial system in Michel's classification. In this study we found a case with an accessory right hepatic artery arising directly from the celiac trunk. In the present study, the origin of accessory hepatic artery is seen from CT (10\%; 1 out of 10 cases), whereas Yamashita et al ${ }^{33}$ has reported the variation in $0.24 \%$ cases (16 out of 5696 cases). This could be because of less number of cases in this study. Knowledge of the celiac trunk, its anatomic patterns and variations is clinically relevant for image studies as well as for esophageal, gastroduodenal, hepatic, biliary, pancreatic, splenic and colonic surgical procedures. 


\section{REFERENCES}

1. David F. Pinal-Garciaa, Carlos M.The Celiac Trunk and Its Anatomical Variations: A Cadaveric Study. J Clin Med Res. 2018;10(4):321-329

2. Zhou Ye, MD, Song Ye, MD. A rare variation of celiac trunk and hepatic artery complicating pancreaticoduodenectomy. Medicine (2017) 96:48(e8969)

3. M. C. Rusu - B. A. Manta. Novel anatomic variation: heptafurcation of the celiac trunk. Surgical and Radiologic Anatomy (2018) 40:457-463

4. Pitman AG, Moss D, Stringer MD. 20 Posterior abdominal wall and retroperitoneum. In: Standring $\mathrm{S}$, Editor Gray's Anatomy. The Anatomical Basis of Clinical Practice.41st ed. Edinburgh: Elsevier. 2015;1083-1097

5. Haller AV. Iconesanatomicae in quibusaliquaepartesCorporishumanidelineataeproponuntu retarteriaumpotissimumhistoriacontinuter. Gottingen. 1756:Vandenhoeck

6. Natalia Valentin, Wilson R Veras, Jhonathan Duarte. A unique branching patern of celiac trunck. Its clinical and embryological significance.9650 Rockville Pike Bethesda, MD 20814. 2013; 301-634-7000.

7. Lipshutz B. A Composite study of the coeliac axis artery.Ann Surg. 1917;65(2):159-169.

8. Michels NA. Blood supply and anatomy of the upper abdominal organs, with a descriptive atlas. Philadelphia:Lippincott. 1955; 139-143.

9. Higashi N, Shimada H, Simamura E, Hatta T. [Branching patterns of the celiac artery as the hepato-gastro-splenic trunk]. KaibogakuZasshi. 2009; 84(1):7-10.

10. Panagouli E, Venieratos D, Lolis E, Skandalakis P. Variations in the anatomy of the celiac trunk: A systematic review and clinical implications. Ann Anat. 2013; 195(6):501-511.

11. Song SY, Chung JW, Yin YH, Jae HJ, Kim HC, Jeon $\mathrm{UB}$, Cho BH, et al. Celiac axis and common hepatic artery variations in 5002 patients: systematic analysis with spiral CT and DSA. Radiology. 2010;255(1):278288.

12. Venieratos D, Panagouli E, Lolis E, Tsaraklis A, Skandalakis P. A morphometric study of the celiac trunk and review of the literature. Clin Anat. 2013; 26(6):741750 .

13. Morita M. Reports and conception of three anomalous cases on the area of the celiac trunk and the superior mesenteric arteries. IgakuKenkyu (Acta Med). 1935; 9:159-172.

14. Chitra R. Clinically relevant variations of the celiac trunk. Singapore Med J. 2010; 51(3):216-219.

15. Nelson TM, Pollak R, Jonasson $\mathrm{O}$, Abcraian $\mathrm{H}$. Anatomic variants of the celiac, superior mesenteric, and inferior mesenteric arteries and their clinical relevance. Clin Anat. 1988;1(2):75-91

16. Mburu KS, Alexander OJ, Hassan S, Bernard $\mathrm{N}$. Variations in the branching pattern of the celiac trunk in a Kenyan population. Int J Morphol. 2010;28(1):199-204.
17. Farghadani M, Momeni M, Hekmatnia A, Momeni F, BaradaranMahdavi MM. Anatomical variation of celiac axis, superior mesenteric artery, and hepatic artery: Evaluation with multidetector computed tomography angiography. J Res Med Sci. 2016;21:129.

18. Iezzi R, Cotroneo AR, Giancristofaro D, Santoro M, Storto ML. Multidetector-row CT angiographic imaging of the celiac trunk: anatomy and normal variants. SurgRadiol Anat. 2008;30(4):303 310.

19. Petrella S, Rodriguez CF, Sgrott EA, Fernandes GJ, Marques SR, Prates JC. Anatomy and variations of the celiac trunk. Int J Morphol. 2007;25(2):249-257.

20. Vandamme JP, Bonte J. The branches of the celiac trunk.ActaAnat (Basel). 1985; 122(2):110-114.

21. Loukas M, Hullett J, Wagner T. Clinical anatomy of the inferior phrenic artery. Clin Anat. 2005; 18(5):357-365.

22. Greig HW, Anson BJ, Coleman SS. The inferior phrenic artery; types of origin in 850 body-halves and diaphragmatic relationship. Q Bull Northwest Univ Med Sch. 1951;25(4):345-350

23. Srivastava AK, Sehgal G, Sharma PK, Kumar N, Singh R, Parihar A, Aga P. Various types of branching patterns of celiac trunk. The FASEB Journal. 2012;26(Suppl 1):722.5.

24. Michels NA. Newer anatomy of the liver and its variant blood supply and collateral circulation. Am J Surg 1966; 112:337-47.

25. Hiatt JR,Gabbay J, Busuttil RW. Surgical anatomy of the hepatic arteriesin 1000 cases. Ann Surg 1994; 220:50-2.

26. Daly JM, Kemeny N, Oderman P, et al. Long-term hepatic arterial infusion chemotherapy. Arch Surg 1984; 119:936-41.

27. Suzuki T,Nakayasu A, Kawabe K, et al. Surgical significance of anatomic variations of the hepatic artery. Am J Surg 1971; 122:505-12.

28. Lanz VT, Wachsmuth W. Lanz/Wachsmuth Practical Anatomy. Springer-Verlag, Berlin: 2003.

29. De Santis M, Ariosi P, Calo GF, et al. Anatomiavascolarearteriosaepatica e sue varianti [Hepatic arterial vascular anatomy and its variants]. Radiol Med 2000; 100:145-51.

30. Koops A, Wojciechowski B, Broering DC, et al. Anatomic variations of the hepatic arteries in 604 selective coeliac and superior mesenteric angiographies. SurgRadiolAnat 2004; 26:239-44.

31. López-And_ujar R, Moya A, Montalvá E, et al. Lessons learned from anatomic variants of the hepatic artery in 1,081 transplanted livers. Liver Transpl 2007; 13:14012140.

32. Chen H, Yano R, Emura S, Shoumura S. Anatomic variation of the celiac trunk with special reference to hepatic artery patterns. Ann Anat. 2009; 191(4):399-407.

33. Yamashita K, Hashimoto D et al. Accessory right hepatic artery branched from gastroduodenal artery. Surg Case Rep. 2015; dec: 1:90.

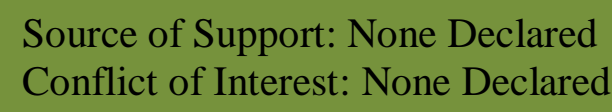

